Article

\title{
Reprocessing of Mining Wastes for the Recovery of Silver by Leaching in the Thiosemicarbazide - Oxygen System
}

\author{
Juan Hernández-Ávila ${ }^{1}$, M. Isabel Reyes-Valderrama ${ }^{1, *}$, Eduardo \\ Cerecedo-Sáenz ${ }^{1}$, Demetrio Mendoza-Anaya ${ }^{2}$, Ventura Rodríguez-Lugo ${ }^{1}$ and \\ Eleazar Salinas-Rodríguez ${ }^{1, *}$
}
1 Academic Area of Earth Sciences and Materials, Institute of Basic Sciences and Engineering. Autonomous University of the State of Hidalgo, Mexico; herjuan@uaeh.edu.mx (J.H.-A.); isareyv@hotmail.com (M.I.R.-V); mardenjazz@yahoo.com.mx (E.C.-S.); ventura.r165@gmail.com (V.R.-L.); salinasr@uaeh.edu.mx(E.S.-R.)
2 National Institute of Nuclear Research; demetrio.mendoza@inin.gob.mx (D.M.-A.)
* Correspondence: isareyv@hotmail.com ; salinasr@uaeh.edu.mx Tel.: +52-771-712-000 ext. 2980

\begin{abstract}
The mining wastes generated during the last decades in the mining region of Pachuca-Real del Monte in Mexico, still contains silver values of interest. For this reason, the present work is a preliminary study of the leaching kinetics of silver contained in these residues, using as a leaching reagent the thiosemicarbazide-oxygen system, with the aim of proposing this leaching system as a less toxic alternative than cyaniding process. Previous the leaching process, representative samples were wholly characterized, finding $56 \mathrm{~g}$ of Ag and $0.6 \mathrm{~g}$ of $\mathrm{Au}$ per ton. For the kinetic study in the mentioned system, were evaluated the reagent concentration, temperature, partial pressure of oxygen, $\mathrm{pH}$ and stirring rate. According the experimental results found, it was observed that $\left[\mathrm{CH}_{5} \mathrm{~N}_{3} \mathrm{~S}\right]$ concentration showed a significant effect on the leaching rate, obtaining a reaction order of $\mathrm{n}=0.93$, in the range of $20-40 \mathrm{~mol} \mathrm{CH}_{5} \mathrm{~N}_{3} \mathrm{~S} \cdot \mathrm{m}^{-3}$, getting so a silver recovery up to $76.9 \%$. The effect of temperature gave an activation energy of Ea = $45.55 \mathrm{KJ} \mathrm{mol}^{-1}$, which was indicative of a chemical reaction control. Finally, partial pressure of oxygen has a notable effect on leaching rate, but $\mathrm{pH}$ and stirring rate have not apparent effect.
\end{abstract}

Keywords: Reprocessing of mining wastes; Leaching of silver; Thiosemicarbazide-oxygen system; No toxic leaching process

\section{Introduction}

In Mexico, mining has been one of the most traditional economic activities since pre-Hispanic times until today. Particularly, in the mining region of Pachuca-Real del Monte, the processing of minerals containing silver and gold, has included technologies that range from the benefit of the yard, the Pachuca tanks and current circuits that involve grinding, flotation and cyaniding [1]. The state of Hidalgo has 
been pioneer in these processes, and due to the processing of minerals that contain gold and silver, during more than 458 years, important volumes of mining wastes have been generated, containing approximately 110 million tons [1] in four dams containing $\mathrm{Ag}$ and $\mathrm{Au}$ values ranging from 25 to $120 \mathrm{~g}$ of $\mathrm{Ag}$ per ton [1-5] and from 0.3 to $1.5 \mathrm{~g}$ of Au per ton $[2-3,5]$.

However, these mining wastes contain pyritic and quartziferous minerals, where the gold and silver values could be encapsulated in particles whose average size is of the order of - $75 \mu \mathrm{m}(60-65 \%)$ [5], which inhibits the extraction of these values. On the other hand, the presence of some elements and cyanide consuming species, do not allow in many cases to achieve an adequate extraction of the values of interest, as well as the silver contained in refractory and jarosite compounds, constitute a metallurgical problem by conventional processes [5-9].

It has been found that the leaching of silver with organic compounds containing in the THIO group (Thiourea $\mathrm{CS}\left(\mathrm{NH}_{2}\right)_{2}$, Thiosulfate $\mathrm{S}_{2} \mathrm{O}_{3}{ }^{2-}$, Thiocyanate $\mathrm{SCN}$ and Thiosemicarbazide $\mathrm{CH}_{5} \mathrm{~N}_{3} \mathrm{~S}$ ), have some advantages with respect to conventional cyaniding, such as the ease of carrying out the dissolution under acidic conditions using strong oxidizing agents, likewise the values can be recovered by means of adsorption or precipitation, in addition to the reactant having a lower toxicity, thus reducing environmental problems.

As it is known, the most studied leaching reagent is thiourea and in the case of thiosemicarbazide, the kinetics and thermodynamics of the system have recently been studied, making use of the rotating disk and using pure silver; obtaining favorable results to carry out new investigations in refractory minerals, as well as in concentrates and tailings from the processing of the same minerals [4]. It is for this reason, that the present work is a kinetiks study carried out to analyze the effectiveness of the thiosemicarbazide-oxygen system, for the extraction of the silver contained in waste from the mining-metallurgical industry, under acid and oxidant conditions; and based on this, determine the optimal conditons of recovery of this precious metal in the system indicated. Likewise, with the development of this project, we have the interest to find new alternatives to the traditional cyaniding process, proposing a leaching with leaching reagents of the Thio family, in this case the Thiosemicarbazide, since they are considered as non-toxic alternatives.

\section{Materials and Methods}

For the kinetics study, samples of $50 \mathrm{~kg}$ from the "Velasco" dam were taken, and prepared to be whole characterized to determine its chemical and mineralogical characterization, using several analytical techniques such as $\mathrm{X}$ - ray Difraction (XRD), $X$ - ray Fluorescence (XRF), Scanning Electron Microscopy (SEM) inconjuction with Energy Dissperssive Spectrometry of $X$ - ray (EDS), Inductive Couple Plasma Spectrometry (ICP) and Atomc Absorption Spectrometry (AAS). Subsequently, the sample was ground in bach type, for 8 minutes at working speed of $71.87 \mathrm{rpm}$ with a ball load of $10.23 \mathrm{~kg}$, a pulp load of $2097.77 \mathrm{~g}, 930 \mathrm{~mL}$ of water 
and a milling unit (Denver brabd) was used with ball mills, from which samples were obtained (All one to 8 minutes of milling) for subsequent leaching [1].

The leaching experiments were carried out in a $1000 \mathrm{~mL}$ flat bottom glass reactor, which was mounted on a magnetic stirring heating plate coupled to a mechanical stirrer workinf at $750 \mathrm{rpm}$ (Figure 1); the $\mathrm{pH}$ was continously measured and adjusted in all experimelnts with the controlled addition of $0.2 \mathrm{M} \mathrm{NaOH}$ solution. Industrial purity oxygen was injected to give a pressure atmosphere inside the reactor. The temperature of the system was controlled by means of a thermocouple to the heating grid.

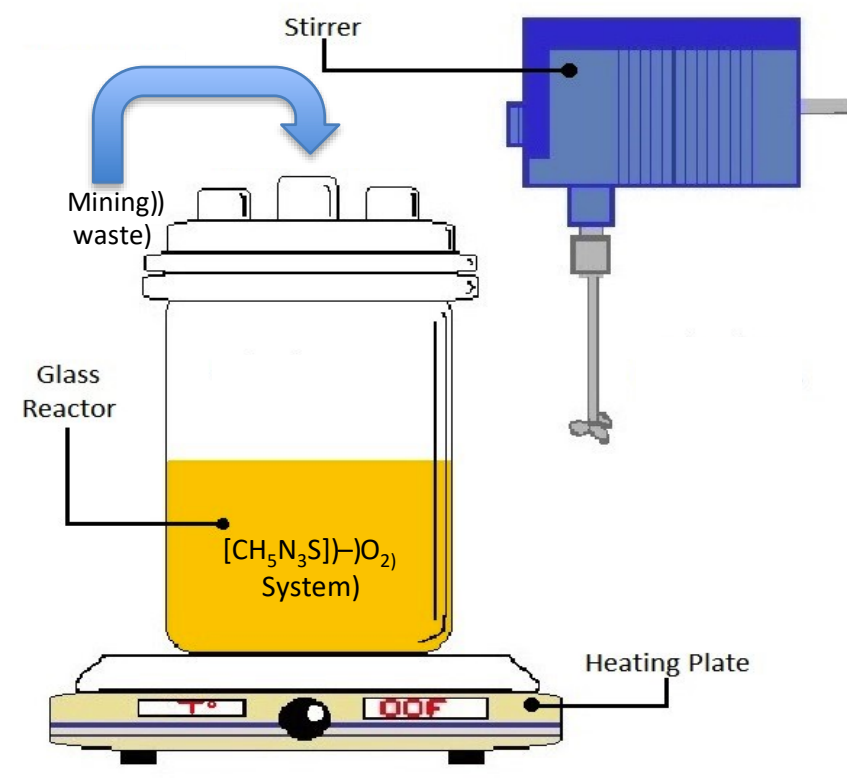

Figure 1. Squematic image of the experimental aparatus used in the leaching experiences

Fort the determination of the weights of each of the samples, an OAHUS digital analytical balance was used, Analytical Plus AP210S model with accuracy of 0.001 mg. The kinetics of leaching with Thiosemicabazide was carried out under the following experimental conditions: $\left[\mathrm{CH}_{5} \mathrm{~N}_{3} \mathrm{~S}\right]$ between 15.8 and $189.6 \mathrm{gL}^{-1}$; the studied temperature was in a range between 288 and $333 \mathrm{~K} ; \mathrm{O}_{2}$ partial pressure of 0.2 and $1 \mathrm{~atm}$; mineral weight of $40 \mathrm{gL}^{-1} ; \mathrm{pH}$ between 4 and 12; volume of solution of $500 \mathrm{~mL}$ and agitation speed between 200 and $800 \mathrm{~min}^{-1}$. During the kinetic study, the $\mathrm{pH}$ was kept constant by adding previously prepared $0.2 \mathrm{M} \mathrm{NaOH}$ solution to the reactor; Likewise, the monitoring of the solubilized $\mathrm{Ag}$ at the different reaction times from 0 to 240 minutes was carried out by analysis by Atomic Abnsorption Spectroscopy. Finally, with the results obtained, the optimal conditions of leaching were determined to obtain the maximum silver recoveries contained in the mining wastes, througth the analysis of the kinetics results obtained, sucha s order of reaction, energy of activation, effect of some kenetics parameters and the determination of the keinetics equation that describes the overall reaction. 
4 of 10

\section{Results and Discussion}

\subsection{Materials Characterization}

The characterization performed by XRF, ICP and AAS confirmed that the chemical composition of mining waste is the presented in Table 1

Table 1. Chemical composition of the mining waste used for leaching of Ag.

\begin{tabular}{ccc}
\hline Element $^{1}$ & $\begin{array}{c}\text { \% wt. } \\
\text { AAS }\end{array}$ & $\begin{array}{c}\text { \% wt. } \\
\text { XRF }\end{array}$ \\
\hline $\mathrm{SiO}_{2}$ & 70.43 & 73.30 \\
$\mathrm{Al}_{2} \mathrm{O}_{3}$ & 7.32 & 6.50 \\
$\mathrm{Fe}_{2} \mathrm{O}_{3}$ & 2.80 & 2.80 \\
${ }^{*} \mathrm{SO}_{3}$ & 1.14 & 0.94 \\
$\mathrm{~K}_{2} \mathrm{O}$ & 0.80 & 0.80 \\
$\mathrm{CaO}$ & 0.69 & 0.69 \\
$\mathrm{Na} 2 \mathrm{O}$ & 2.32 & 0.08 \\
$\mathrm{MgO}$ & 0.54 & 0.55 \\
$\mathrm{TiO}$ & 0.53 & 0.30 \\
$\mathrm{MnO}$ & 0.73 & 0.73 \\
$\mathrm{P}_{2} \mathrm{O}_{5}$ & 0.12 & 0.12 \\
$\mathrm{Ag}$ & $51 \mathrm{~g} /$ ton & $56 \mathrm{~g} /$ ton \\
\hline
\end{tabular}

${ }^{1}$ Elements as oxides, except silver, ${ }^{*}$ Determined by ICP

The principal mineral species identified by XRD were; Silica, Berlinite, Orthoclase, feldspar, Anortoclasa, Calcite, Gypsum, Hematite, Pyrite, Sphalerite, Galena and Chalcopyrite, which is observed in the Figure 2

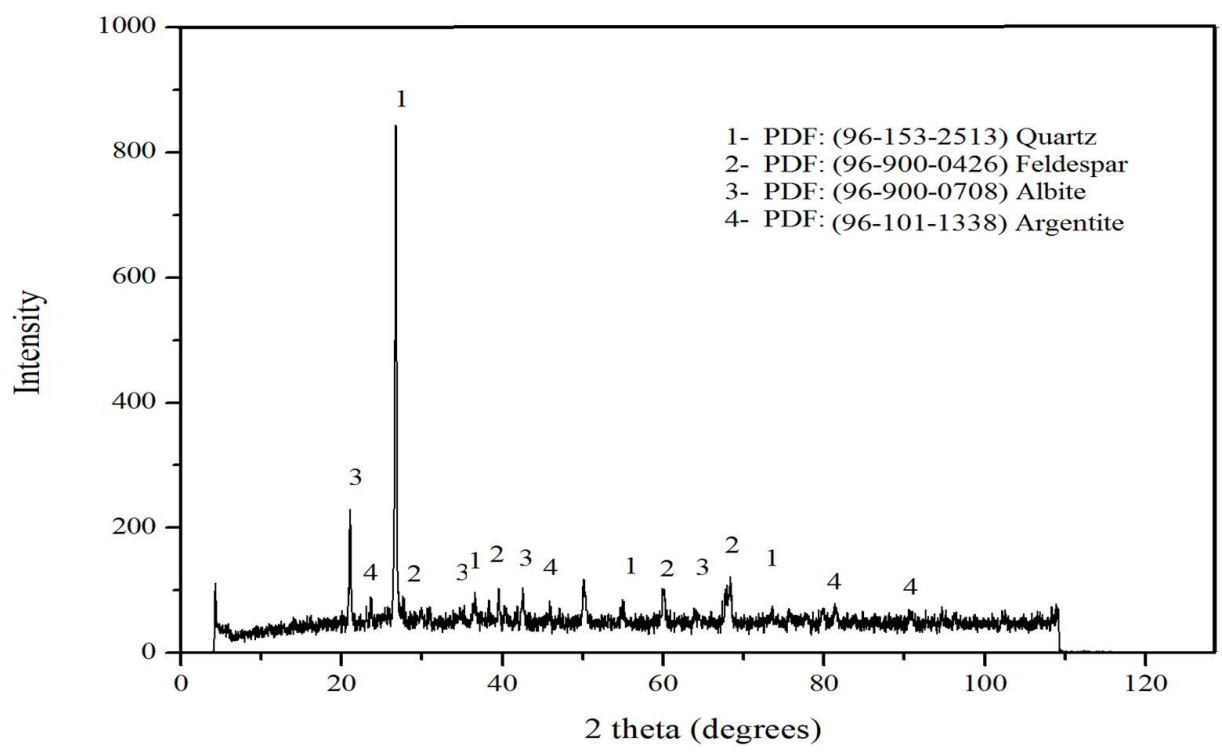

Figure 2. XRD spectrum of the mining waste from "Velasco" dam 
On the other hand, Figure 3 shows the general image of particle distribution in the minins wastes, and a particular image of a particule of the material, observing the compact structure of it and the irregular form of particles invoved in the material.

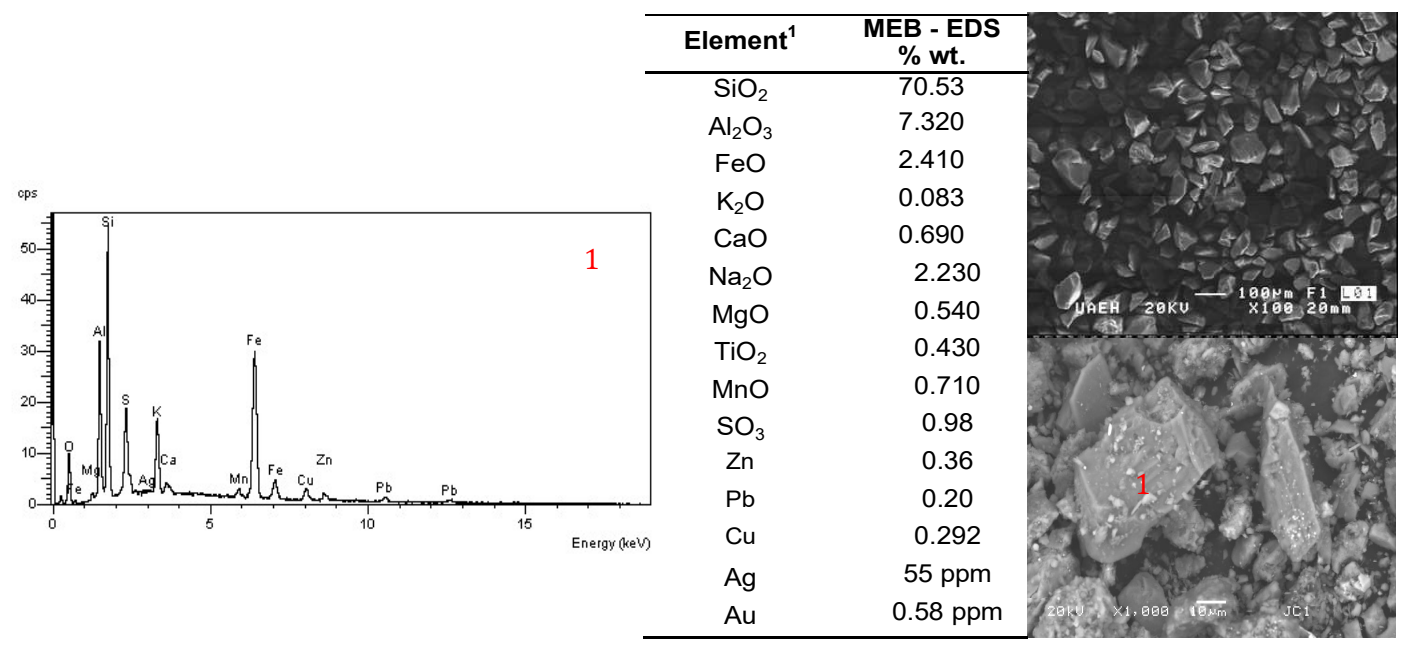

Figure 3. SEM images of general particle distribution, EDS spectra and punctual analysis

\subsection{Kinetics study of silver leaching in thiosemicarbazide media}

The study of alkaine leaching of mining wastes to extract silver contained, was executed to determine the influence of $\left[\mathrm{CH}_{5} \mathrm{~N}_{3} \mathrm{~S}\right]$ concentration, temperature, $\mathrm{pH}$, stirring rate and $\mathrm{O}_{2}$ partial pressure.

\subsubsection{Effect of Thiosemicarbazide concentration}

The effect of $\left[\mathrm{CH}_{5} \mathrm{~N}_{3} \mathrm{~S}\right]$ concentration on the $\mathrm{Ag}$ leaching rate is shown in Figure 4. The order of reaction was 0 in the range between 10 and $20 \mathrm{~mol} \cdot \mathrm{m}^{-3}\left[\mathrm{CH}_{5} \mathrm{~N}_{3} \mathrm{~S}\right]$ and increase to 0.93 in the range between 20 and $40 \mathrm{~mol} \cdot \mathrm{m}^{-3}\left[\mathrm{CH}_{5} \mathrm{~N}_{3} \mathrm{~S}\right]$, and finally fell in the range between 40 and $50 \mathrm{~mol} \cdot \mathrm{m}^{-3}\left[\mathrm{CH}_{5} \mathrm{~N}_{3} \mathrm{~S}\right]$ giving again an order of reaction of 0 . In the same figure, it is noted that above $40 \mathrm{~mol} \cdot \mathrm{m}^{-3}$ and below $20 \mathrm{~mol}$ $\cdot \mathrm{m}^{-3}$, there was a change of order of reaction, reaching a value of 0 , which means that at these particular points there was a change in reaction mechanisms, being in the first stage (from 10 to 20), due to chemical reaction is fast but diffusion of reactant to particle surface is slow. And above $40 \mathrm{~mol} \cdot \mathrm{m}^{-3}$ the excess of reactant could retard the diffusion of products of reaction to inner of solution. 


\section{6 of 10}

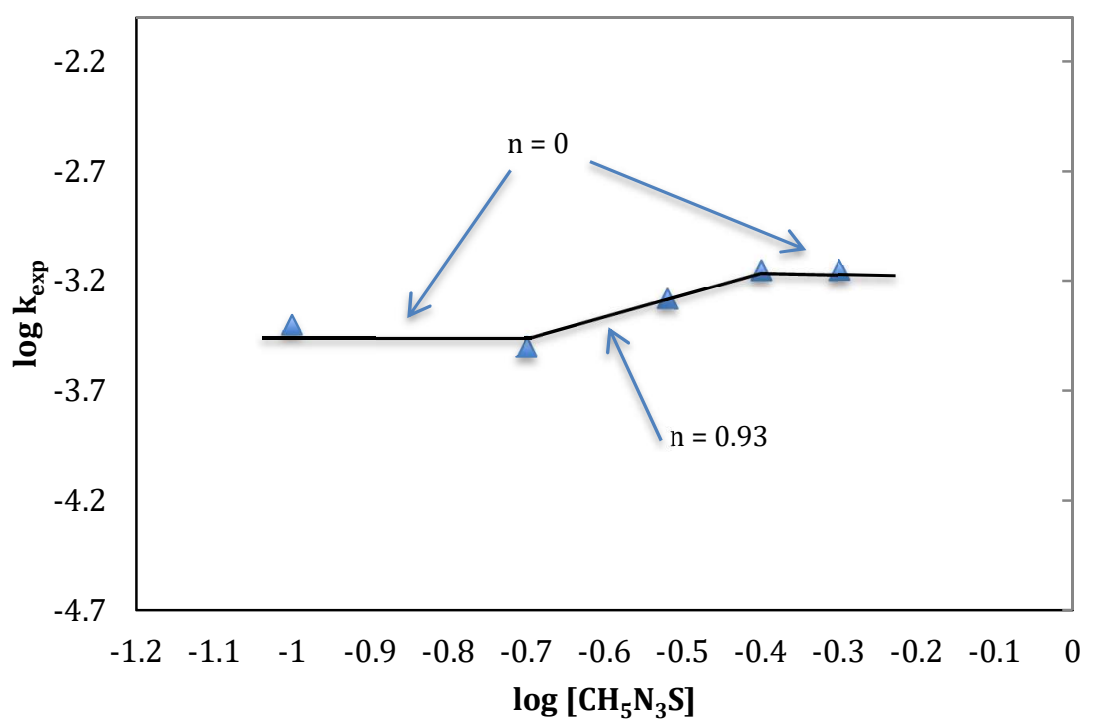

Figure 4. Leaching of Ag in the Thiosemicarbazide - oxygen system: Effect $\left[\mathrm{CH}_{5} \mathrm{~N}_{3} \mathrm{~S}\right]$ concentration

The phenomenon of a reaction order change also could be due that at low concentrations of thiosemicarbazide the silver leaching rate depends essentially on the complexing itself and the partial pressure of oxygen; however, as can be observed in the same Figure 4 from a certain concentration of thiosemicarbazide, the leaching rate remains stable and is not affected by the concentration of the complexing, passing the leaching rate to depend solely on the dissolved oxygen concentration in the system.

The effect of temperature is shown in figure 5. The activation energy obtained was $45.55 \mathrm{~kJ} \mathrm{~mol}^{-1}$, which fell in the range of $288 \mathrm{~K}$ to $328 \mathrm{~K}\left(15{ }^{\circ} \mathrm{C}\right.$ to $\left.55{ }^{\circ} \mathrm{C}\right)$ and describes that chemical reaction is the controlling stage in the leaching of silver contained in mining wastes, in the thiosemicarbazide - oxygen system.

On the other hand, the effect of stirring rate is shown in Figure 6, where can be observed practically no effect of this variable on the Ag leaching, which could be due to the chemical control observed during the process of leaching and determined by the activation energy found. 


\section{7 of 10}

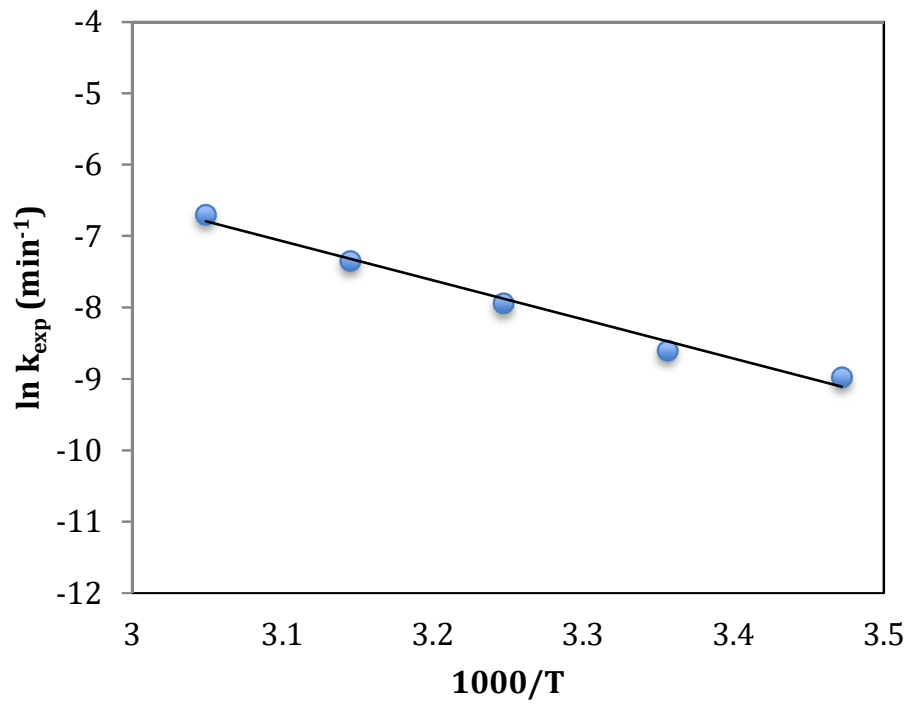

Figure 5. Leaching of Ag in the Thiosemicarbazide - oxygen system: Effect of temperature, $E_{a}=45.55 \mathrm{~kJ}$. $\mathrm{mol}^{-1}$

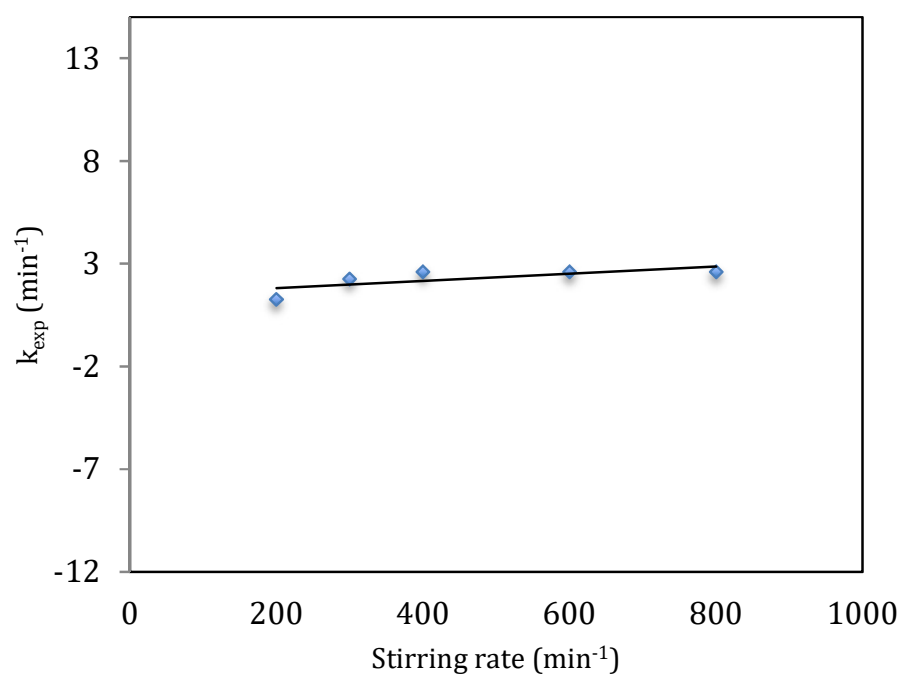

Figure 6. Leaching of Ag in the Thiosemicarbazide - oxygen system: Effect of stirring rate

The effect of $\mathrm{O}_{2}$ partial pressure is shown in Figure 7, where can be observed a strong dependence of this variable on the silver leaching rate, increasing the recovery of silver from $33 \%$ in a $0.2 \mathrm{~atm} \mathrm{O}_{2}$ partial pressure up to a $60 \%$ in a $1 \mathrm{~atm}$ $\mathrm{O}_{2}$ partial pressure, which confirms that increasing oxygen in system leaching reaction is improved. 
8 of 10

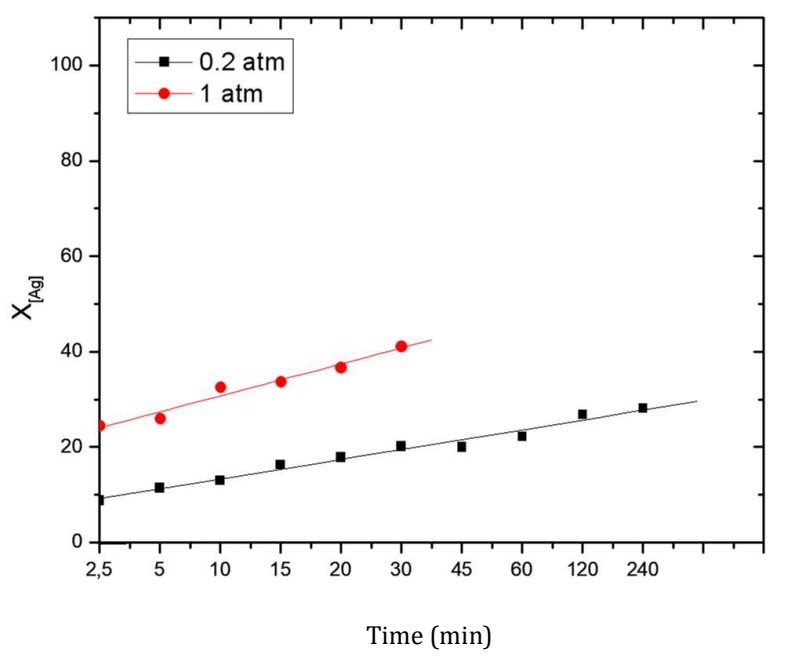

Figure 7. Leaching of Ag in the Thiosemicarbazide - oxygen system: Effect of $\mathrm{O}_{2}$ partial pressure

Finally, the effect of $\mathrm{pH}$ is shown in Figure 8 where can be seen that the $\mathrm{pH}$ has no significant effect on $\mathrm{Ag}$ leaching rate in the range from 4 to 12, confirming again that oxygen concentration promotes strongly the Ag leaching from mining wastes.

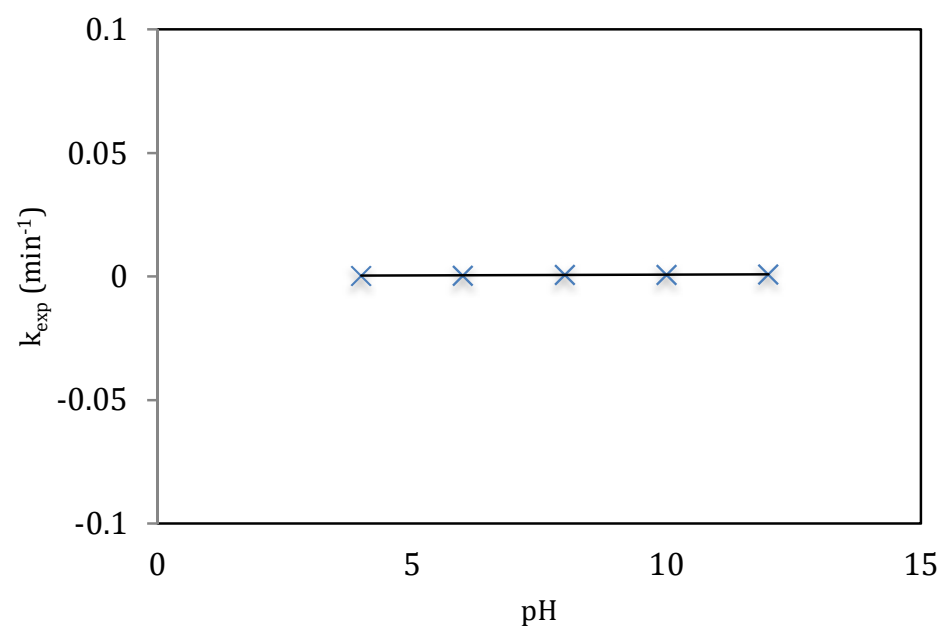

Figure 8. Leaching of Ag in the Thiosemicarbazide - oxygen system: Effect of $\mathrm{pH}$

According to the results found, the kinetics expression determined in the $\mathrm{CH}_{5} \mathrm{~N}_{3} \mathrm{~S}-\mathrm{O}_{2}$ media, is the following for the range of concentrations from 20 to 40 $\mathrm{mol}\left[\mathrm{CH}_{5} \mathrm{~N}_{3} \mathrm{~S}\right] \cdot \mathrm{m}^{-3}$ :

$\mathrm{r}_{0} / \mathrm{V}_{\mathrm{M}}\left[1-(1-\mathrm{X})^{1 / 3}\right]=1.84 \times 10^{4} \exp ^{(-45550 / \mathrm{RT})}\left[\mathrm{CH}_{5} \mathrm{~N}_{3} \mathrm{~S}\right]^{0.93} \cdot \mathrm{t} \quad-(1)$ 
9 of 10

where $V_{M}=265.0 \times 10^{-6} \mathrm{~m}^{3} \cdot \mathrm{mol}^{-1}, R=8.314 \mathrm{~J} \cdot \mathrm{mol}^{-1} \mathrm{~K}^{-1}, r_{0}$ in $\mathrm{m}, T$ in degrees Kelvin, $\left[\mathrm{CH}_{5} \mathrm{~N}_{3} \mathrm{~S}\right]$ is in $\mathrm{mol} \cdot \mathrm{m}^{-3}$, and $\mathrm{t}$ is in seconds.

Finally, the overall reaction carried during the leaching process is the following:

$$
\mathrm{Ag}+\mathrm{CH}_{5} \mathrm{~N}_{3} \rightarrow \mathrm{Ag}\left(\mathrm{CH}_{5} \mathrm{~N}_{3} \mathrm{~S}\right)^{+1}+1 e^{-}
$$

\section{Conclusions}

During the leaching of silver in the thiosemicarbazide-oxygen system contained in the mining waste, it was observed that the increase in the concentration of thiosemicarbazide, also increases the silver dissolved in the leaching solution, being $38 \%$ when using $10 \mathrm{~mol}\left[\mathrm{CH}_{5} \mathrm{~N}_{3} \mathrm{~S}\right] \cdot \mathrm{m}^{-3}$ and up to $76 \%$ for a concentration of $30 \mathrm{~mol}$ $\left[\mathrm{CH}_{5} \mathrm{~N}_{3} \mathrm{~S}\right] \cdot \mathrm{m}^{-3}$ at room temperature. The order of reaction was $\mathrm{n}=0$ in the ranges between 10 and $20 \mathrm{~mol}\left[\mathrm{CH}_{5} \mathrm{~N}_{3} \mathrm{~S}\right] \cdot \mathrm{m}^{-3}$ and between 40 and $50 \mathrm{~mol}\left[\mathrm{CH}_{5} \mathrm{~N}_{3} \mathrm{~S}\right] \cdot \mathrm{m}^{-3}$, while in the range between 20 and $40 \mathrm{~mol}\left[\mathrm{CH}_{5} \mathrm{~N}_{3} \mathrm{~S}\right] \cdot \mathrm{m}^{-3}$, the reaction order has a value of $n=0.93$, which reflects a change of mechanism in the leaching reaction. On the other hand, the increase in temperature had a marked influence on the degree of dissolution of the silver, because it was observed that the recovery of the precious metal increased from $32 \%$ to $91 \%$, going from 288 to $328 \mathrm{~K}$ ( 15 to $55 \mathrm{C}$ ) respectively, using $30 \mathrm{~mol}\left[\mathrm{CH}_{5} \mathrm{~N}_{3} \mathrm{~S}\right] \cdot \mathrm{m}^{-3}$. The activation energy (Ea) found was $45.55 \mathrm{~kJ} \mathrm{~mol}^{-1}$, a value that is indicative that the process is controlled by the chemical reaction. So according to the results the proposed system can be considered an alternative to treat refractory minerals, because under certain conditions, maximum solutions of $91 \%$ of $\mathrm{Ag}$ are reached.

Likewise, it was identified that the $\mathrm{pH}$ practically does not have a significant effect in the leaching of the silver contained in the treated mining waste. Finally it was found that partial pressure of oxygen has a significant effect on silver leaching.

Author Contributions: Conceptualization, J.H.-A. and E.S.-R.; Methodology, J.H.-A and M.I.R.-V.; Formal Analysis, J.H.-A., M.I.R.-V., E.S.-R. and V.R.-L.; Investigation, M.I.R.-V., D.M.-A.; Resources, E.C.-S., J.H.-A. and M.I.R.-V.; Data Curation, J.H.-A. and E.S.-R.; Writing-Original Draft Preparation, E.S.-R.; Writing-Review \& Editing, V.R.-L. and E.S.-R.; Visualization, J.H.-A. and E.C.-S.; Supervision, M.I.R.-V.; Project Administration, J.H.-A. and E.S.-R.; Funding Acquisition, M.I.R.-V, J.H.-A. and E.S.-R.

Funding: Publication funded with PFCE 2018 resources.

Acknowledgments: The authors would like to thank SEP-PRODEP. Also thanks go to the National Institute of Nuclear Research and the Autonomous University of the State of Hidalgo, Mexico.

Conflicts of Interest: The authors declare no conflict of interest.

\section{References}

1. Juan, H. A., Eleazar, S. R., Francisco, P. C., Isauro, R. L., Martín, R. P., Miguel, P. L., ...\& Eduardo, C. S. Characterization of Burrows from Mining District of Pachuca-Real Del Monte, in Hidalgo State and Viability Study to Use These Residues as Alternate Industrial Material. In EPD Congress 2011 (pp. 73-80). John Wiley \& Sons, Inc..CRM. (1992). Monografía Geológico-Minera del Estado de Hidalgo. México: CRM. 
2. Eleazar Salinas R., Francisco Patiño C., Juan Hernández A., Leticia E. Hernández Cruz, Isauro Rivera L., la problemática de los jales en el estado de Hidalgo, Memoria del IV Congreso Nacional de Metalurgia y Materiales, pp. 237-328, México, septiembre 2006.

3. Hernandez, J., Salinas, E., Patino, F., Rivera, I., Flores, J., Trapala, N. \& Reyes, I. (2012). Tile Production Using Wastes from Mining Industry of the Mining District Pachuca and Real Del Monte. In AIP Conference Proceedings. American Institute of Physics, Ste. 1 NO 1 Melville NY 11747-4502 United States.

4. Oraby, E. A., Browner, R. E., \&Nikraz, H. R. (2012). Effect of Silver in Thiosulfate Leaching of Gold-Silver Alloys in the Presence of Copper and Ammonia Relative to Pure Gold and Silver. Mineral Processing and Extractive Metallurgy Review, 25-32.

5. Hernandez, J., Patino, F., Rivera, I., Reyes, I. A., Flores, M. U., Juarez, J. C., \& Reyes, M. (2014). Leaching kinetics in cyanide media of Ag contained in the industrial mining-metallurgical wastes in the state of Hidalgo, Mexico.International Journal of Mining Science and Technology.

6. Hernández, J., Rivera, I., Patiño, F., \& Juárez, J. C. (2013). Estudio Cinético de la Lixiviación de Plata en el Sistema $\quad \mathrm{S} 2 \mathrm{O} 3 \quad$ (2-)-O2-Cu2+ Contenido Residuos Minero-Metalúrgicos. Informacióntecnológica, 24(1), 51-58.

7. C. Abbruzzese, P. Fornari, R. Massidda, F. Veglio. 'Thiosulphate leaching for gold hydrometallurgy', Hydrometallurgy, Vol. 39, pp. 265-276 1995.

8. Salinas-Rodríguez, E., Hernández-Ávila, J., Rivera-Landero, I., Cerecedo-Sáenz, E., Reyes-Valderrama, M. I., Correa-Cruz, M., \& Rubio-Mihi, D. (2016). Leaching Of Silver Contained In Mining Tailings, Using Sodium Thiosulfate: A Kinetic Study. Hydrometallurgy, 160, 6-11.

9. Barrientos, F. R., Flores M.A. (1996). Estudio del comportamiento de la tiosemicarbazida sobre lixiviación de un mineral de plata (Tesis no publicada) Universitad Autonoma del Estado de Hidalgo. 